\title{
Preparing Latinx College Students for Leadership in California
}

\author{
Ronald S. Glickman \\ California State University, Los Angeles
}

With a majority Latinx population in California and the future of the state's economy depending on college educated leaders, it is important to develop a deeper understanding of how Hispanic Serving Institutions (HSIs) in the state can better prepare Latinx students for leadership in the workforce. In this qualitative case study, the author investigated the experiences of four first-generation college students in an undergraduate leadership course at an HSI and their perceptions about how their experiences in the course influenced their beliefs about leadership and their behavior in the workforce.

Keywords: Hispanic-Serving Institutions (HSIs), Latinx college students, first generation college students, self-authoring theory, authentic leadership theory, leadership development programs

\section{INTRODUCTION}

California is facing a serious shortage of college educated workers with the job skills and leadership competencies to support the eighth largest economy in the world ${ }^{1}$. If current trends in the labor market persist, the state of California will have a shortage of 1.1 million college educated workers by 2030 (Johnson, Mejia, \& Bohn, 2015). Therefore, California's higher education system is a critical driver of the state's economic progress. While college graduates are more likely to be employed and earn higher wages than non-graduates, which increases state tax revenues and reduces social services costs, Jackson and Johnson of the Public Policy Institute of California (2018), a nonpartisan research institution that focuses on population issues, the economy, governance, and public finance, declared that "California's higher education system is not keeping up with the changing economy" (p. 1). This problem is exacerbated by the imminent retirement of the Baby Boomers in California (a population of 8.4 million people born between 1945 and 1964), which represents the first time in the state's history that such a large well-educated generation will be exiting the workforce (Johnson et al., 2015; Maciag, 2015).

The Baby Boomer generation was influenced by an industrial leadership paradigm that was largely transactional, where leadership was experienced as an individual, hierarchical, and operational activity (Eich, 2008). In the post-industrial leadership paradigm of the twenty-first century, leadership is more transformative and experienced as a collaborative partnership between leaders and followers (Dugan, 2006). Komives, Lucas, and McMahon (2013) define this modern leadership paradigm as "a relational and ethical process of people together attempting to accomplish positive change" (p. vii), whereas Northouse (2016) describes it as "a process whereby an individual influences a group of individuals to achieve a common goal" (p. 6). Notably, in this context it is possible for an individual to engage formally or informally in the leadership process as a leader, follower, subordinate, or committed member of a group or team (Komives et al., 2013). This paradigm shift means that the generation of well-educated 
college graduates who replace the Baby Boomers must develop job skills and modern leadership competencies to succeed in the workforce. The shift from transactional leadership where leaders are born, to transformative leadership where leaders are made, means that twenty-first century leadership competencies can be taught and college students who involve themselves in leadership education have the potential to increase their job skills and leadership knowledge (Dugan, Kodama, \& Gebhardt, 2012; Eich, 2008; Northouse, 2016)

Latinx ${ }^{2}$ people are now the majority ethnic population in California and enrolling in college in increasing numbers (Valliani, 2015). In 2016, almost half (41.2\%) of the undergraduate students in the state were Latinx people (Hispanic Association of Colleges and Universities [HACU], 2018). Hispanic Serving Institutions (HSIs) play a critical role in the postsecondary education of this population because these institutions collectively enroll nearly two-thirds of all Latinx students in postsecondary education (Excelencia in Education, 2018). The growing demand for well-educated college graduates to replace the Baby Boomers in the California economy make modern leadership competencies important educational priorities for Latinx students, especially at HSIs that have a mission to serve them.

\section{REVIEW OF THE LITERATURE}

In an effort to understand the factors influencing the preparation of Latinx college students for leadership in the California workforce, it is important to examine the issues surrounding HSIs, leadership development courses, and the non-cognitive variables that influence the motivation and persistence of Latinx college students in higher education.

\section{HSIs’ EVOLVING ORGANIZATIONAL IDENTITIES AND MEASURES OF SUCCESS}

Defined by the federal government as a postsecondary institution that enrolls $25 \%$ or more undergraduate Latinx students, the HSI began as a political construct that reflected a national interest in addressing the low college-going and educational attainment of Latinx students in the U.S. (Santiago, 2012). The defining characteristic of these institutions was a concentrated enrollment of Latinx students, not an overt institutional mission to serve them (Hubbard \& Stage, 2009; Hurtado \& Ruiz, 2012; Santiago, 2012). However, a growing number of minority-majority ${ }^{3}$ jurisdictions in the U.S. (e.g., California) is driving the need for HSIs and other minority serving institutions to better serve populations that have been systemically oppressed and historically discriminated against in postsecondary education (Garcia, 2017; Garcia \& Okhidoi, 2015). The combination of factors used to measure what it means to be Latinx-serving are collectively referred to by Garcia (2017) as an HSI's organizational identity. The author's study focused specifically on HSIs, suggesting that organizational identities that incorporate both institutional results and cultural ways of knowing may improve outcomes for Latinx college students. However, there is still scant research available about improving success in the labor market for Latinx college graduates, one of the key measures identified by Garcia (2017) to define an HSI's Latinx-serving organizational identity.

\section{CRITICAL SUCCESS FACTORS OF HIGH QUALITY LEADERSHIP DEVELOPMENT PROGRAMS}

In their seminal study of 31 Kellogg Foundation-funded leadership development projects, Zimmerman-Oster and Burkhardt (1999) concluded that leadership potential exists in every student and found that colleges and universities can develop this potential through intentional, high-quality leadership development programs. In this context, leadership is defined as a "relational and ethical process of people together attempting to accomplish positive change" (Komives et al., 2013, p. 11). This definition is widely accepted in teaching leadership to college students and is aligned with the leadership definition and philosophy defined by the Council for the Advancement of Standards in Higher Education (CAS), a consortium of professional associations in higher education that promote the use of standards for the 
development, assessment, and improvement of quality student learning programs (Council for the Advancement of Standards in Higher Education, 2015; Dugan, 2006; Eich, 2008). Quality is defined by the effectiveness and efficiency with which high-quality leadership development programs deliver student learning and leadership development outcomes for program participants (Eich, 2008).

High-quality leadership development programs aim to influence how learners think about leadership and increase their level of self-knowledge and capacity to engage others in collaborative work (Cohen et al., 2013; Darling-Hammond, LaPointe, Meyerson, Orr, \& Cohen, 2007; Dugan, 2006; Komives, Owen, Longerbeam, Mainella, \& Osteen, 2005). Drawing on the perspectives of participants at four successful leadership programs in the U.S., Eich (2008) identified three programmatic themes associated with highquality leadership development programs: building and sustaining a learning community, creating experiential learning experiences, and engaging in continuous improvement activities. Decades of research documents the benefits of high-quality leadership development programs (Dugan, 2006; Eich, 2008; Zimmerman-Oster \& Burkhardt, 1999). When compared to non-participants, students who participated in high-quality leadership development programs were more likely to report meaningful improvements on the measured leadership development outcomes of self-understanding, ability to set goals, sense of ethics, willingness to take risks, civic responsibility, multicultural awareness, community orientation, and a variety of leadership competencies (Eriksen, 2009; Jones \& Abes, 2004; Teranishi, 2007). In addition, students in these programs reported increased theoretical knowledge about leadership, as well as an interest and willingness to develop leadership in others (Eich, 2008; Zimmerman-Oster \& Burkhardt, 1999). However, these results do not necessarily reflect the experiences of Latinx students at HSIs in the U.S. or, more specifically, in the state of California.

\section{NON-COGNITIVE VARIABLES THAT INFLUENCE MOTIVATION AND PERSISTENCE}

Student persistence is a major concern for most universities. This is especially true in California where the six-year graduation rate gap between White and Latinx students has increased from 13\% among the first year cohort enrolling in 1998 to $14 \%$ for the cohort enrolling in 2007 in the CSU system, and from 5\% among the first year cohort enrolling in 2000 to $7 \%$ for the cohort enrolling in 2009 in the UC system (Valliani, 2015). While students attending higher education institutions enter with a wide range of personal attributes, family background, academic skills, financial resources, and precollege academic experiences (Tinto, 1993), non-cognitive variables, such as positive self-concept and the availability of supportive individuals, can be more predictive of academic success in college for minority students than traditional measures of cognitive skills such as standardized test scores and GPA (Fuertes \& Sedlacek, 1994; Dennis, Phinney, \& Chuateco, 2005).

Clearly, the preparation of Latinx college students for leadership in the California workforce will require an intentional effort by HSIs in the state to develop high quality leadership development programs that focus on college student development, in general, and leadership development, in particular, while addressing the needs of students from underrepresented backgrounds. The conceptual framework for this research was purposefully selected to provide a theoretical lens through which to explore the efforts at one HSI in California towards this aim.

\section{CONCEPTUAL FRAMEWORK}

This study draws from the existing literature on theoretical understandings of authentic leadership and self-authorship. Authentic leadership theory asserts that leaders possess self-awareness, clear beliefs and values, and the desire to serve others (George, Sims, Mclean, \& Mayer, 2007; Komives et al., 2013). Selfauthorship theory, defined as the internal capacity to define one's beliefs, identity, and social relations, provides a framework for understanding how college students develop a strong sense of self (Magolda, 2004). College students must be able to develop and define a set of core values that define a strong sense of self in order to develop into authentic leaders (Eriksen, 2009). Therefore, this study incorporates a College Student Leadership Development Framework (see Figure 1) that draws from the existing 
literature on self-authorship and authentic leadership to take into account what is required for college students from underrepresented backgrounds to become authentic leaders and how HSIs in California can tailor instruction to support their personal growth and leadership development accordingly.

\section{FIGURE 1 COLLEGE STUDENT LEADERSHIP DEVELOPMENT FRAMEWORK}

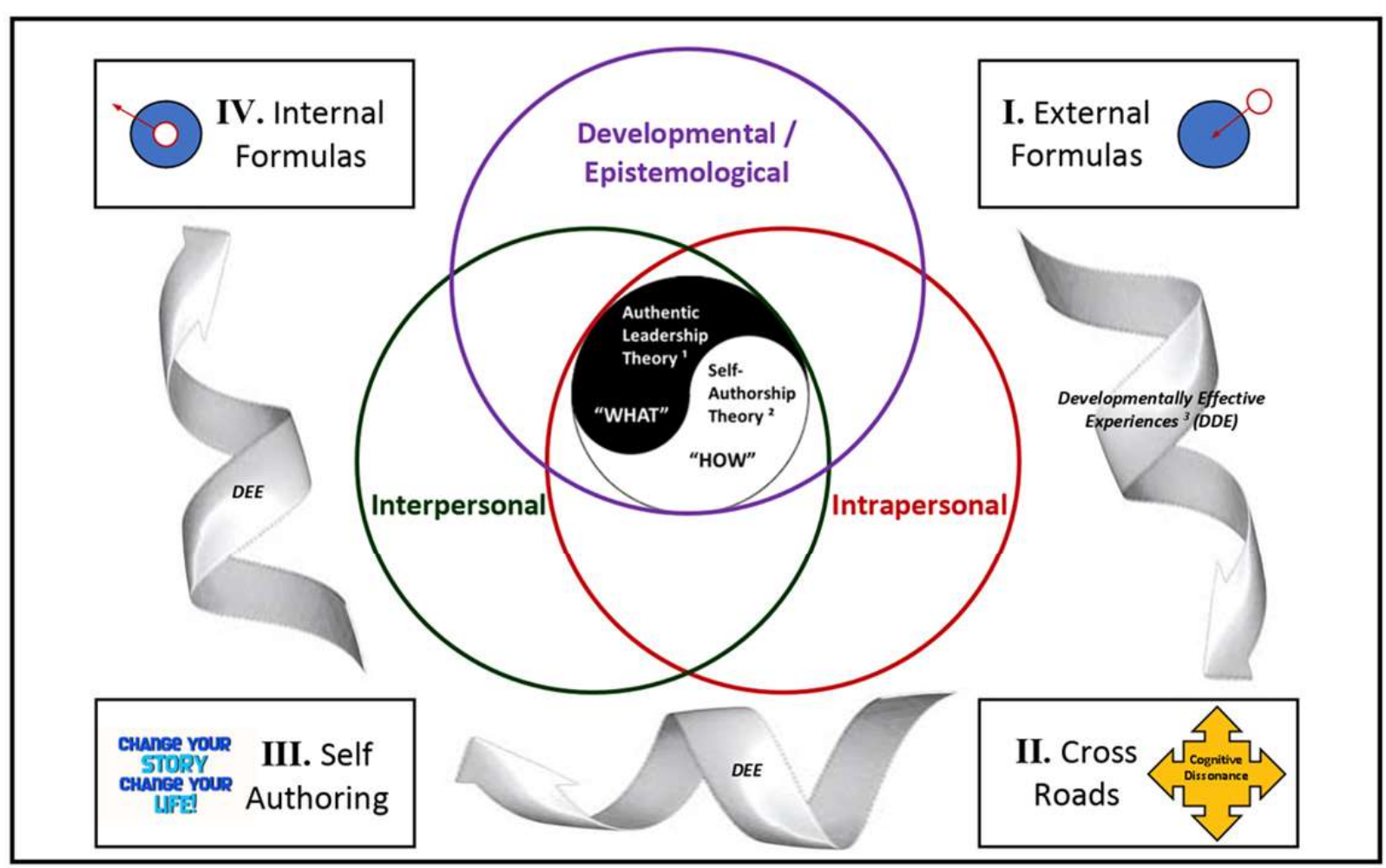

Figure 1. College Student Leadership Development Framework. 1) Authentic leaders have a genuine desire to serve others, know themselves, and lead from a set of core beliefs and values. (Eriksen, 2009; George, Sims, McLean, \& Mayer, 2007; Komives, Lucas, \& McMahon, 2013; Northouse, 2016). 2) Developing the capacity to think contextually and behave in ways that are congruent with one's belief system are central components of self-authorship (Barber \& King, 2014; Carpenter \& Peña, 2017; Magolda, 2004; Pizzolato, 2005; Torres \& Hernandez, 2007). 3) Developmentally effective experiences foster cognitive dissonance and prompt exploration, reflection and, ultimately, developmental growth (Carpenter \& Peña, 2017; Magolda, 2009; Northouse, 2016).

\section{PURPOSE OF THE STUDY}

With a majority Latinx population in California and the future of the state's economy depending on college educated leaders, it is important to develop a deeper understanding of how HSIs in the state can better prepare Latinx students for leadership in the workforce. This investigation will contribute to a growing body of research that addresses the needs of college students from underrepresented backgrounds, and aims to provide data that will inform ongoing efforts to effectively tailor instruction to the needs of this population in preparing them for successful careers in their field of their choice after college.

\section{RESEARCH QUESTIONS}

The following research questions guided this study: 
1) What were the experiences of first generation Latinx students in an undergraduate leadership course at a Hispanic serving institution?

2) How did their experiences in the undergraduate leadership course influence their beliefs about leadership and their behavior in the workforce?

\section{METHODOLOGY}

The boundaries for this qualitative case study were an undergraduate leadership course (i.e., the case activity) taught in the College of Business and Economics (CBE) at a regional public comprehensive university in Southern California in 2017 and 2018 (i.e., the case timeframe). The upper division elective course, entitled Management Leadership and Motivation (MLM), encourages students to carefully analyze their responsibilities and commitments to leadership aligned with the university's strategic intent to deliver leading edge academic programs that prepare students to be innovative leaders and serve their local communities. The class is taught by adjunct or part-time instructors (rather than full-time tenure track faculty) with professional business and organizational leadership experience, and includes the study and application of different theories of leadership, along with a focus on developing students' cognitive, interpersonal, and intrapersonal competencies for personal growth and preparation for leadership in the workforce. Students from a variety of majors within the CBE, such as accounting, operations management, and human resources, may choose to enroll in the class as an undergraduate elective.

The purposeful sampling approach for this study targeted research participants who were most likely to yield a rich set of data for examining the experiences of first generation Latinx students in an undergraduate leadership course at an HSI, and how their experiences in the course influenced their beliefs about leadership and their behavior in the workforce. Ultimately, four MLM students and the professor who taught the course were recruited to participate. All of the student participants were fully employed adult learners and varied in age, gender, ethnicity, and occupation (see Table 1).

\section{TABLE 1}

\section{PARTICIPANT SUMMARY}

\begin{tabular}{lllllll}
\hline Pseudonym & Role & Gender & Age & Ethnicity & Term & Occupation \\
\hline Angel & Student & Male & 43 & Hispanic & Spring 2017 & Retired Soldier \\
Diana & Student & Female & 30 & Latina & Spring 2017 & Legal Assistant \\
Nueve & Student & Male & 43 & Mexican & Spring 2017 & Warehouse Mgr. \\
Steve & Student & Female & 32 & White & Fall 2017 & Consultant \\
Professor Garcia & Professor & Male & 60 & Hispanic & Spring and Fall & Tech. Executive \\
& & & & & 2017 & \\
\hline
\end{tabular}

In-depth, open-ended interviews were the primary source of data collected for this study. The interview process followed a protocol outlined by Seidman (2005) and informed by phenomenology to identify the essence of the human experiences described by the participants. Using Seidman's protocol (2005) as a guide, we interviewed each participant two times, where the first interview focused on their life history and the second on their experiences in the leadership course and their subsequent reflections accordingly. In addition, a small sample of pre- and post-course questionnaires were selected to add depth and capture insights from multiple perspectives (Creswell, 2014; Maxwell, 2013). More specifically, 8 verifiable pairs of pre- and post-course questionnaires were selected from a total sample of 147 pre- and post-course questionnaires to augment the participant interview data and examine any changes in the students' perceptions, values, beliefs, and knowledge about themselves and leadership that resulted from their experiences in the MLM course. Three specific strategies were used to foster trustworthiness: member checking, triangulation, and memoing. 


\section{FINDINGS}

Two primary themes that illustrated the participants' experiences in an undergraduate leadership course at an HSI and their perceptions about their experiences within and beyond the workforce: (1) the professor created a cross-roads learning environment, where (2) the participants experienced growth across the three common developmental dimensions of self-authorship and authentic leadership theories.

\section{CREATING A CROSSROADS LEARNING ENVIRONMENT}

The crossroads phase of self-authorship theory is comprised of two distinct steps. The first involves exploring one's own beliefs and values and establishing a distinction between one's internal feelings and other's external expectations (Magolda, 2009). This step is often fostered by cognitive dissonance, prompting individuals "to question their epistemological, intrapersonal, and interpersonal frameworks" (Carpenter \& Peña, 2017, p. 88). The second step involves self-reflection, where individuals reinforce their important beliefs, sift out those that are no longer relevant, and create a more independent internal voice with a commitment to fostering it (Magolda, 2009; Carpenter \& Peña, 2017). All of the participants implied that Professor Garcia created a learning environment that challenged their attitudes, beliefs and behaviors in a manner that prompted cognitive dissonance and propelled them into the crossroads phase of self-authorship. Their reflections centered around three key ideas: creating a safe environment to learn and grow, engaging and empowering students, and being a strong role model, especially for Latinx students.

\section{Creating a Safe Environment to Learn and Grow}

The crossroads phase of self-authorship involves the development of an internal voice by questioning external authorities and resolving conflicts that arise from the cognitive dissonance associated with challenges to epistemologies embraced in the external formulas phase of self-authorship (Carpenter \& Peña, 2017). A crossroads experience has been described as a provocative moment or experience resulting from "jarring disequilibrium" (Pizzolato, 2005, p. 625) that prompts a student's commitment to, as opposed to simply the recognition of, the need to work toward self-definition (Magolda, 2004; Pizzolato, 2005). Experiencing an imbalance between what one understands going into the class and what one encounters in the classroom can provoke fear or apprehension, thwarting the learning process. Therefore, it is imperative that a crossroads learning environment feel safe for students to take risks and explore new attitudes, beliefs and behaviors. The participants expressed the notion that Professor Garcia created such an environment in the MLM classroom by being approachable, open-minded, and transparent. Nueve reflected that "it was just natural to take the info without feeling threatened, compromised or belittled or what have you." Angel agreed, stating:

If you make students feel part of what's going on and explain and give them the whole picture, then they take more interest in it. They feel like they have ownership of what's going on and people work a lot better that way.

The participants felt that Professor Garcia was approachable and created a learning environment in the MLM class that was conducive for embracing provocative (i.e., crossroads) experiences as an opportunity for learning and growth rather than a barrier to progress.

\section{Engaging and Empowering Students}

In addition to experiencing a safe environment to learn and grow, Professor Garcia was intentional about involving student voice in the classroom from the beginning of the course in order to encourage engagement: 
Rather than asking in general "hey does everybody understand that?" I identify one or two individuals and ask them to stand up and explain what the lesson meant to them and how it fits with their experiences. Initially the classrooms are quiet, but one of the best things you can do is keep your mouth shut, wait, and give them permission to sit down if they're uncomfortable. Eventually, they speak and you build a culture within the class where it's perfectly okay to speak and it's perfectly okay to give a different opinion than the professor or the rest of the class.

Almost all of the participants corroborated Professor Garcia's perception that encouraging students to speak up was a positive experience. Angel said:

One of the big things was he would always have everybody give feedback by asking "what did you get from it?" "what did you like?" and "what didn't you like?" Everybody loved the fact that they were forced to talk.

Diana confirmed this, sharing that "I liked the fact that everyone would come together to share our thoughts or stories with the entire class." Both of them shared positive student learning outcomes from engaging in this manner. Angel indicated that "I feel more prepared for my next, you know, classes or challenge" and Diana declared that "it affected me in a positive way. I learned not be afraid to speak my mind, to be more vocal, and not to hold back because, as Professor Garcia always said, there's no wrong answer."

In addition to proactively engaging students by inviting their voices into discussion, Professor Garcia empowered them by creating opportunities for students to practice their emergent leadership skills in the classroom. Steve shared that "he let us be leaders in the class; he kind of stepped back and let us take over and really shape and form the class the way we wanted." For example, Diana described an activity where the students decided to work in groups to practice interviewing skills:

When you're interviewing you need to be confident, so we decided to work in groups of four to try it amongst each other. By the third time we felt more comfortable. I thought that was a really cool way of getting used to interviewing in the real world and I learned, you know, I learned.

Reflecting on the same experience, Steve said that "it really taught me more than just reading it out of a book. It wasn't about rinsing and repeating facts. It was about actually understanding how you put things into practice. This was learning it and retaining it." Angel agreed, sharing his perception that "if you practice theory, you're going to retain it more." By actively engaging participants in the learning process and allowing them the freedom to determine how to engage in certain circumstances, Professor Garcia fostered a crossroads learning environment where students gained confidence and internalized important student learning outcomes.

\section{Being a Strong Role Model, Especially for Latinx Students}

Access to subject matter experts and accomplished leaders who the participants viewed as examples to be emulated was the third key factor in creating a crossroads learning environment. Seeing that Professor Garcia was an accomplished Latinx professional was especially salient for the Latinx students whose responses reflected the underrepresentation of Latinx faculty members, even at an HSI. Diana spoke about the power of learning from someone with a similar background

It's a predominantly Latino school so being able to have a professor, you know, with the similar Latino background means a lot. He came from a hardworking family. He speaks Spanish. He grew up in similar circumstances that I did. It's empowering to see that 
there's other people that have walked the same path that I have or that I will. Little factors like that are very important because you're able to relate.

Nueve made a similar point but spoke about the power of learning from someone who was different than he expected to be teaching a leadership class:

When you look at someone that's trying to give a leadership class, you hate to say it but sometimes you look at the color first. You say "wait a minute, it's easy for you because you're white." That's so bad to like feel that way but where I grew up you don't see a lot of people that are white and most of the times they're the landlords, they're someone in a suit, you know. So, yeah. I think it's easier for [Latinx] students because Professor Garcia was Latino.

Angel agreed with Diana and Nueve that Professor Garcia was a positive role model, saying that "it shows, you know, that if you really want it, you can do it. The professor is a prime example, you know, he has his education; I mean if he can do it, why not?"

In addition to having Professor Garcia as a Latinx role model, Nueve and Angel talked about the benefits of having exemplary guest speakers share their personal stories and experiences with the students. According to Nueve:

In most classes you just have one professor and you may have one guest speaker, but in this class it was nice to have different speakers come in from different angles to reiterate some of the points that the class was trying to make.

Angel agreed:

It was cool to see and hear from them. "Hey, I went through this. I was in that chair." That's the kind of thing that people need to be hearing because you can't get that from books; that's their own stuff.

In summary, I found that the student participants' descriptions about Professor Garcia's persona and approach in the classroom depicted a crossroads learning environment that was conducive to growth across the three developmental dimensions of the self-authorship and authentic leadership theories.

\section{GROWING ACROSS THE COMMON DEVELOPMENTAL DIMENSIONS OF SELF- AUTHORSHIP AND AUTHENTIC LEADERSHIP THEORIES}

Developmentally effective experiences, defined as learning experiences that fundamentally change a student's beliefs, values or behaviors (Barber et al., 2013; King, Magolda, Barber, Brown, \& Lindsay, 2009), are an important catalyst for growth across the developmental dimensions of self-authorship and authentic leadership theories. In the constructivist tradition of these theories, such experiences aim to surface the interconnectivity of how students view the world (i.e., the epistemological dimension), how they see themselves (i.e., the intrapersonal dimension), and how they view social relations (i.e., the interpersonal dimension), fostering cognitive dissonance and prompting exploration, reflection and, ultimately, developmental growth (Carpenter \& Peña, 2017; Magolda, 2009; Northouse, 2016). The following section describes three developmentally effective experiences that the participants recognized as most meaningful to their growth across the developmental dimensions of self-authorship and authentic leadership theories. 


\section{DiSC $®$ Personality and Behavior Profile}

The developmentally effective learning experience singled out by the participants as an essential catalyst for intrapersonal growth was the DiSC $₫$ exercise. The DiSC $₫$, published by Wiley, is a nonjudgmental tool used for discussion of individual behavioral differences. Participants answer a series of questions that produce a detailed report about their personality and behavior. The report provides a common language that people can use to better understand themselves and adapt their behaviors with others. Professor Garcia described the exercise as follows:

We brought in an outside subject matter expert to do what's called a DiSC® profile that teaches about how you like to communicate and what's your best way to communicate with others. We did some workshops with the students all working together to understand each other's communication styles and I think that helped a lot with their awareness of self and others.

Several participants corroborated Professor Garcia's assertion that the exercise had an impact. According to Steve:

I realized fairly quickly, which I would not have realized before this experience, that other people are not motivated by change. In fact, it scares them. So being able to shape the wording, shape the perception of what a change program will do for them, instead of what is being taken away from them, helped it go a lot smoother at work than it would have.

Diana also talked about understanding herself better and relating differently to others; she said "now I'm able to see someone else's opinion and, at the same time, be able to acknowledge their opinion without being offended by it; now I need to hear other people because I'm not always right."

Nueve talked about a change in his approach when communicating with his team at work, where he is a Warehouse Manager responsible for the flow of goods to and from the facility:

So at first I was very authoritarian, very disciplined, you know, it's my way or the highway. Now I try to emphasize not what I want to tell them is right, but more what I would want to hear in that situation and what is going to make it feel better. Now the way I talk to them and the way I present information to them is all different because I'm aware that the way I talk to people can have an impact.

Diana summed up her DiSC $®$ experience, saying "I had never experienced anything like it; it was just different but different in a good way." Steve agreed, sharing that "it was the little things I was able to pick up that made a huge change."

\section{Leadership Style Analysis}

The developmentally effective learning experience singled out by the participants as an essential catalyst for interpersonal growth was The Leadership Style Analysis (LESTAN) exercise. This activity helped the participants understand that effective leaders with strong interpersonal skills take other people's perspectives into account when making important decisions. LESTAN distinguishes five levels of participation and 11 situational factors that influence the effects of teamwork on decision quality, implementation, time, and team development. The exercise enables managers to examine their own implicit assumptions about the consequences of sharing their decision-making power (Vroom, 2003). Professor Garcia described the exercise as follows:

We brought in a senior executive from a top global consulting firm to help students understand different ways that leaders can involve team members when making 
decisions. He used the LESTAN model to facilitate discussions about 30 short cases that describe a leader in a decision-making situation where some kind of action was required. The students talked about how they, as the leader in each case, would make the decision and why. It was great because they learned about many different ways to solve the same problem and that there was usually more than one right way to do things.

While Steve was the only participant to talk extensively about this exercise, she had the following reflection about learning a different way to think about decision making:

I never honestly thought of different decision styles. I've always just experienced someone telling me what to do and so that's what I do. My input didn't matter. So, because that's always how it came down to me, that's how I expected it to go down from me. After taking this, I realized that, depending on the situation, it doesn't always produce the best result to do it that way. It was never really something I thought about before. I was just doing what the people before me did.

\section{Vision Boards}

The developmentally effective learning experience singled out by the participants as an essential catalyst for meaning making was a vision board exercise aimed at clarifying what students wanted to be, do or have in their lives. In this activity, students assessed their leadership strengths and opportunities, set personal leadership goals, described their vision through pictures and words, and presented it to the class in five minutes or less. Professor Garcia described the vision board exercise as follows:

Part of self-awareness development included the students doing a vision board, where they have to ask: if they knew they could not fail, what would they do with their lives? This was phenomenal because $99 \%$ of them came up with something altruistic where they wanted to do something good for the world, good for their family, or good for their friends and everybody else. The vision board activity helped students understand who they really are and what really drives them.

At first, some participants were skeptical about this activity. Steve thought "it was going to be stupid," while Nueve thought "cutting out pictures and pasting them on paper takes you back to kindergarten." However, both of them reflected very different perspectives at the end of the assignment. Steve shared that "I have always been a creature of habit and I think the vision board process let me come outside of this and see what else is around; it was a mind opener." Nueve also saw things differently, expressing that "you get a chance to look at the opportunity and decide if you want it or not, versus, the other way, here's an opportunity take it. So there's a choice and that's what makes you free." In addition, Nueve said this about his vision board:

I still have it. I took it out the other day and I'm like, okay, I'm doing some of those things. Okay, it's good to have that goal and be able to say that you're close to it or that you've done it. It's a powerful tool and a powerful visual.

Diana also talked extensively about the vision board activity. One of her insights was that "it was very interesting to see everyone else's vision board presentation and how many of us from different cultures, not just Latino, had similar goals." She also shared specifics about her own experience:

When I made it, I got a little bit emotional because I'm like, "oh my God, I'm actually doing this. These are my set goals. This is where I want to be in five years." It doesn't matter what culture you are or, you know, what descent you are, because you have a 
vision for yourself, a long-term goal. It's there and you just have to follow it. That was very empowering.

The aforementioned developmentally effective experiences changed the participants' beliefs and behavior, helping them think differently about themselves and demonstrate authentic leadership potential by working more effectively with others.

\section{DISCUSSION}

\section{New Ways of Knowing}

College students acquire knowledge and make meaning from developmentally effective experiences based on their individual epistemologies or ways of knowing. Magolda (1992) named two such individual epistemologies: absolute and transitional ways of knowing. Absolute knowers make professors the focal element in the learning process, value the transmission of knowledge from teacher to student, and define success by "knowing the material;" whereas transitional knowers privilege student involvement in the learning experience, value professors who are approachable and excited about teaching, and define success based on the knower's freedom to "understand, apply, and think about [the] material" (Magolda, 1992, p. 282).

All of the participants in this small sample were grounded in more transitional ways of knowing. Their reflections about Professor Garcia's success in creating a safe environment to learn and grow, engaging and empowering his students, and being a strong role model, especially for Latinx students, were indicative of their beliefs that student involvement, caring professors, and applying what they learned inside and outside of the classroom fostered meaning making from their developmentally effective experiences. Steve and Nueve shared insights that most clearly represented shifts in their beliefs and behaviors resulting from their experiences in the MLM course. In general, Nueve indicated that "I'm treating people different than I was before and I myself feel different than I have before. Now I feel a little bit more powerful."

Steve also shared a shift in her thinking about the importance of interpersonal skills:

This class made me think differently. You know, who cares if you can run a regression line, like that doesn't matter. Unless you know how to interact with people and get along with people and understand people and work with people, your regression line really doesn't matter; no one cares.

\section{Expanded Images of Leadership}

In addition to the meaningful belief changes disclosed by Steve and Nueve, the most profound changes resulting from the developmentally effective experiences in the MLM course were the participants' beliefs about who can become a leader. Steve shared a macro-level perspective: "coming out of the class, I realized that anyone really can be a leader; it's just important to use those leadership skills for something that's good that's going to help change the world in a positive way." Nueve shared a more specific insight:

I learned in the class that I didn't need to be born into some kind of affluent society to become a leader, but that you could take this class and practice and learn and hone it until you master it. I feel like now I have been able to grow some wings, look at different opportunities that are out there, and say, wait a minute, I can lead. I'm a leader. I can do this.

He went on to share a current example: 
So fast forward to today: I'm applying for a job that, when I looked at it, it was too much. I would never be able to do that. But then I was like, wait a minute, I have the experience, I have the can-do attitude and, most importantly, I have a lot of these leadership skills now.

Several of the students who completed the post-course survey echoed similar shifts in perspective. One commented that "I do believe I am a leader because anyone can be a leader," while another indicated that "I used to think that leaders were born leaders and others just didn't have that luck. No way. I accept that there are people with traits to become leaders, but you can also learn to be a great leader." A third and final example summed up a student's experience as follows: "I really learned so much about being a leader from taking this class. I am so glad that I chose it. I will take the lessons learned with me for a lifetime." According to Professor Garcia, these outcomes were intentional:

The curriculum was designed to help students realize that leaders are made, not necessarily born. A lot of them felt like, well, you know, I'm not white and I'm not male, so I can't be a leader. However, after taking this class they felt like they can certainly be a leader or, at least, that it wasn't necessarily the handicap that they thought it was.

\section{IMPLICATIONS FOR PRACTICE}

Concluding their discussion of self-authorship amongst first-generation undergraduate students, Carpenter \& Peña (2017) made the following assertions:

Institutions must be more intentional in designing co-curricular and curricular experiences to provide provocative learning opportunities [for undergraduate students]... Such learning opportunities must challenge students to examine their current ways of knowing, to critically evaluate their internal belief systems, and to develop healthy mutual relationships. (p. 98)

This research shed light on the impact of an intentionally designed curriculum and classroom experience that provoked first-generation college students in a leadership course at an HSI to examine their attitudes and beliefs about leadership, while strengthening their behaviors at work by applying what they were learning in class on the job. The findings suggest several considerations for leadership development educators at HSIs and the administrators who support them. First, the results from this study support previous proposals that administrators at HSIs should carefully consider whether their hiring practices yield talent with the background and knowledge to support Latinx students in culturally relevant ways (Ching, 2019; Garcia, 2017). Next, the findings support existing evidence suggesting that a deeper level of learning takes place as a result of developmentally effective experiences (Pizzolato, 2005). Therefore, faculty who are designing high quality leadership development courses should aim to surface the interconnectivity of how students view the world (i.e., the epistemological dimension), how they see themselves (i.e., the intrapersonal dimension), and how they view social relations (i.e., the interpersonal dimension), fostering cognitive dissonance and prompting exploration, reflection and, ultimately, developmental growth (Carpenter \& Peña, 2017; Magolda, 2009; Northouse, 2016). Finally, the most salient changes resulting from the developmentally effective experiences in the MLM course were meaningful shifts in the participants' internal beliefs about who can become a leader. Therefore, since more than $50 \%$ of the students who enrolled in the MLM course over a two year period were majoring in disciplines other than business or economics, administrators at HSIs may want to consider positioning an interdisciplinary, high quality, leadership development course in their institution's general curriculum rather than solely in the curriculum of a specific academic discipline or college. 


\section{IMPLICATIONS FOR RESEARCH}

The results of this study elucidate the potential impact that a crossroads learning environment can have on the three developmental dimensions of self-authorship and authentic leadership for first generation college students at an HSI. However, there were several limitations that may impact the generalizability of the results. First, the limited number of participants (i.e., sample size) from a single HSI may not be indicative of the larger community of Latinx college students. In addition, the diversity among the Latinx population is a potential limitation because it is difficult to represent all of the cultures incorporated under this label. Finally, the students who participated in this study illustrated their unique experiences, yet did not necessarily represent the full breadth of diversity in the Latinx college student population, in general, or the SoCalHSI student population enrolled in the MLM course, in particular.

One opportunity to explore the generalizability of these findings is a longitudinal research study designed to clarify the long term effects of the student learning outcomes from a high quality leadership class at an HSI by tracking the participants' experiences in the workforce for several years after graduation. Another opportunity is to examine, more thoroughly, the finding that the participants of this study benefited from applying what they were learning in the MLM course where they were working while taking the class. This finding suggests an opportunity for leadership development professors to create assignments for employed students to practice at work what they are learning in the classroom. Since the majority of Latinx college students must work to finance their education and support themselves (Santiago, 2011), this pedagogical approach would be particularly relevant for Latinx students (or others who work while attending college) enrolled in a leadership development course at an HSI.

Addressing one or more of these opportunities for future research may yield insights that will help HSIs better serve a growing population of Latinx students and prepare them for 2030 when an estimated 1.1 million new jobs in California will be waiting for college educated workers with the leadership knowhow to collaborate with others to achieve a common goal or accomplish positive change.

\section{ENDNOTES}

1. International Monetary Fund, World Economic Outlook Database. (June 11, 2014).

2. I am using the term Latinx as a non-gendered, umbrella term to refer to people of Latin American origin or descent, whereas the term Hispanic is only used in reference to the federal designation of HSIs.

3. Defined as a jurisdiction where the population comprises less than $50 \%$ non-Latinx whites. 


\section{REFERENCES}

Barber, J. P., \& King, P. M. (2014). Pathways toward self-authorship: Student responses to the demands of developmentally effective experiences. Journal of College Student Development, 55(5), 433450. https://doi.org/10.1353/csd.2014.0047

Barber, J. P., King, P. M., \& Magolda, M. B. B. (2013). Long strides on the journey toward selfauthorship: Substantial developmental shifts in college students' meaning making. The Journal of Higher Education, 84(6), 866-896. https://doi.org/10.1353/jhe.2013.0033

Carpenter, A. M., \& Peña, E. V. (2017). Self-authorship among first-generation undergraduate students: A qualitative study of experiences and catalysts. Journal of Diversity in Higher Education, 10(1), 86-100. https://doi.org/10.1037/a0040026

Ching, C. D. (2019). Supporting Latinx students in Hispanic-Serving Institutions: An exploration of faculty perceptions and actions. Journal of Latinos and Education. https://doi.org/10.1080/15348431.2019.1612398

Cohen, J., Cook-Sather, A., Lesnick, A., Alter, Z., Awkward, R., Decius, F., \& Mengesha, L. (2013). Students as leaders and learners: Towards self-authorship and social change on a college campus. Innovations in Education and Teaching International, 50(1), 3-13. https://doi.org/10.1080/14703297.2012.746511

Council for the Advancement of Standards in Higher Education. (2015). CAS learning and development outcomes. In J. B. Wells (Ed.), CAS professional standards for higher education (9th ed.). Washington, DC: Author. Retrieved from https://www.cas.edu/content.asp?contentid=190

Creswell, J. W. (2014). Research design: Qualitative, quantitative, and mixed methods approaches. Thousand Oaks, CA: SAGE Publications.

Darling-Hammond, L., LaPointe, M., Meyerson, D., Orr, M. T., \& Cohen, C. (2007). Preparing school leaders for a changing world: Lessons from exemplary leadership development programs. Stanford, CA: Stanford University, Stanford Educational Leadership Institute.

Dennis, J. M., Phinney, J. S., \& Chuateco, L. I. (2005). The role of motivation, parental support, and peer support in the academic success of ethnic minority first-generation college students. Journal of College Student Development, 46(3), 223-236. https://doi.org/10.1353/csd.2005.0023

Dugan, J. P. (2006). Explorations using the social change model: Leadership development among college men and women. Journal of College Student Development, 47(2), 217-225. https://doi.org/10.1353/csd.2006.0015

Dugan, J. P., Kodama, C. M., \& Gebhardt, M. C. (2012). Race and leadership development among college students: The additive value of collective racial esteem. Journal of Diversity in Higher Education, 5(3), 174-189. https://doi.org/10.1037/a0029133

Eich, D. (2008). A grounded theory of high-quality leadership programs: Perspectives from student leadership development programs in higher education. Journal of Leadership \& Organizational Studies, 15(2), 176-187. https://doi.org/10.1177/1548051808324099

Eriksen, M. (2009). Authentic leadership: Practical reflexivity, self-awareness, and self-authorship. Journal of Management Education, 33(6), 747-771. https://doi.org/10.1177/1052562909339307

Excelencia in Education. (2018). Hispanic-Serving Institutions (HSIs) Fact Sheet: 2016-17. Retrieved from https://www.edexcelencia.org/research/infographics/hispanic-serving-institutions-hsis-201617

Fuertes, J. N., \& Sedlacek, W. E. (1994). Predicting the academic success of Hispanic college students using SAT scores. College Student Journal, 28(3), 350-352. Retrieved from https://www.projectinnovation.com/college-student-journal.html

Garcia, G. A. (2017). Defined by outcomes or culture? Constructing an organizational identity for Hispanic-Serving Institutions. American Educational Research Journal, 54(1), 111S-134S. https://doi.org/10.3102/0002831216669779 
Garcia, G. A., \& Okhidoi, O. (2015). Culturally relevant practices that "serve" students at a Hispanic Serving Institution. Innovative Higher Education, 40(4), 345-357. https://doi.org/10.1007/s10755-015-9318-7

George, B., Sims, P., McLean, A. N., \& Mayer, D. (2007). Discovering your authentic leadership. Harvard Business Review, 85(2), 129. Retrieved from https://hbr.org/2007/02/discovering-yourauthentic-leadership

Hispanic Association of Colleges and Universities. (2018). 2018 fact sheet: Hispanic higher education and HSIs. Retrieved from https://www.hacu.net/images/hacu/OPAI/2018_HSI_FactSheet.pdf

Hubbard, S. M., \& Stage, F. K. (2009). Attitudes, perceptions, and preferences of faculty at Hispanic serving and predominantly Black institutions. The Journal of Higher Education, 80(3), 270-289 https://doi.org/10.1080/00221546.2009.11779013

Hurtado, S., \& Ruiz, A. (2012). Realizing the potential of Hispanic-Serving Institutions: Multiple dimensions of institutional diversity for advancing Hispanic higher education. Retrieved from https://www.hacu.net/hacu/H3ERC_Research_Initiative.asp

Jackson, J., \& Johnson, H. (2018). California is facing a shortfall of college-educated workers. Retrieved from Public Policy Institute of California. Retrieve from http://www.ppic.org/publication/californias-future-higher-education/

Johnson, H., Mejia, M. C., \& Bohn, S. (2015). Will California run out of college graduates? Retrieved from Public Policy Institute of California website: http://www.ppic.org/publication/willcalifornia-run-out-of-college-graduates/

Jones, S. R., \& Abes, E. S. (2004). Enduring influences of service-learning on college students' identity development. Journal of College Student Development, 45(2), 149-166. https://doi.org/10.1353/csd.2004.0023

King, P. M., Magolda, M. B. B., Barber, J. P., Brown, M. K., \& Lindsay, N. K. (2009). Developmentally effective experiences for promoting self-authorship. Mind Brain and Education, 3(2), 108-118. https://doi.org/10.1111/j.1751-228X.2009.01061.X

Komives, S. R., Lucas, N., \& McMahon, T. R. (2013). Exploring leadership: For college students who want to make a difference (3rd ed.). San Francisco, CA: Jossey-Bass.

Komives, S. R., Owen, J. E., Longerbeam, S. D., Mainella, F. C., \& Osteen, L. (2005). Developing a leadership identity: A grounded theory. Journal of College Student Development, 46(6), 593-611. https://doi.org/10.1353/csd.2005.0061

Maciag, M. (2015). Are some government jobs gone for good? Governing, 28(9), 54-55. Retrieved from $\mathrm{http}: / /$ mimas.calstatela.edu/login?url=http://search.ebscohost. com/login. aspx?direct $=$ true $\& \mathrm{db}=\mathrm{of}$ m\&AN $=103228067 \&$ site $=$ ehost-live

Magolda, M. B. B. (1992). Students' epistemologies and academic experiences: Implications for pedagogy. The Review of Higher Education, 15(3), 265-287. https://doi.org/10.1353/rhe.1992.0013

Magolda, M. B. B. (2004). Making their own way: Narratives for transforming higher education to promote self-development. Sterling, VA: Stylus Publishing, LLC.

Magolda, M. B. B. (2009). The activity of meaning making: A holistic perspective on college student development. Journal of College Student Development, 50(6), 621-639. https://doi.org/10.1353/csd.0.0106

Maxwell, J. A. (2013). Qualitative research design: An interactive approach (3rd ed.). Thousand Oaks, CA: SAGE Publications.

Northouse, P. G. (2016). Leadership: Theory and practice (7th ed.). Thousand Oaks, CA: SAGE Publications.

Pizzolato, J. E. (2005). Creating crossroads for self-authorship: Investigating the provocative moment. Journal of College Student Development, 46(6), 624-641. https://doi.org/10.1353/csd.2005.0064

Santiago, D. A. (2011). Roadmap for ensuring America's future by increasing Latino college completion. Washington, DC: Excelencia in Education. Retrieved from https://eric.ed.gov/?id=ED517165 
Santiago, D. A. (2012). Public policy and Hispanic-Serving Institutions: From invention to accountability. Journal of Latinos and Education, 11(3), 163-167. https://doi.org/10.1080/15348431.2012.686367

Seidman, I. (2005). Interviewing as qualitative research: A guide for researchers in education and the social sciences (3rd ed.). New York, NY: Teachers College Press.

Teranishi, C. S. (2007). Impact of experiential learning on Latino college students' identity, relationships, and connectedness to community. Journal of Hispanic Higher Education, 6(1), 52-72. https://doi.org/10.1177/1538192706294946

Tinto, V. (1993). Leaving college: Rethinking the causes and cures of student attrition (2nd ed.). Retrieved from http://mimas.calstatela.edu/login?url=http://search.ebscohost.com/login.aspx?direct=true \&db=eri c\&AN=ED371658\&site $=$ ehost-live

Torres, V., \& Hernandez, E. (2007). The influence of ethnic identity on self-authorship: A longitudinal study of Latino/a college students. Journal of College Student Development, 48(5), 558-573. https://doi.org/10.1353/csd.2007.0057

Valliani, N. (2015). The state of higher education in California: Latino report. Retrieved from https://collegecampaign.org/portfolio/april-2015-state-of-higher-education-in-california-thelatino-report/

Vroom, V. H. (2003). Educating managers for decision making and leadership. Management Decision, 41(10), 968-978. https://doi.org/10.1108/00251740310509490

Zimmerman-Oster, K., \& Burkhardt, J. C. (1999). Leadership in the making: A comprehensive examination of the impact of leadership development programs on students. Journal of Leadership \& Organizational Studies, 6(3-4), 50-66.

https://doi.org/10.1177/107179199900600304 